\section{$\underset{\substack{\text { hommes } \\ \text { \& migrations }}}{ }$}

\section{Hommes \& migrations}

Revue française de référence sur les dynamiques

migratoires

1305 | 2014

L'exil chilien en France

\title{
Des étoiles
}

Film franco-sénégalais de Dyana Gaye

\section{Anaïs Vincent}

\section{Q OpenEdition}

1 Journals

\section{Édition électronique}

URL : http://journals.openedition.org/hommesmigrations/2771

DOI : 10.4000/hommesmigrations. 2771

ISSN : 2262-3353

\section{Éditeur}

Musée national de l'histoire de l'immigration

\section{Édition imprimée}

Date de publication : 1 janvier 2014

Pagination : 195

ISBN : 978-2919-040261

ISSN : $1142-852 X$

\section{Référence électronique}

Anaiis Vincent, « Des étoiles », Hommes \& migrations [En ligne], 1305 | 2014, mis en ligne le 16 juillet 2014, consulté le 22 septembre 2020. URL : http://journals.openedition.org/hommesmigrations/2771 ; DOI : https://doi.org/10.4000/hommesmigrations.2771

Ce document a été généré automatiquement le 22 septembre 2020.

Tous droits réservés 


\title{
Des étoiles
}

\author{
Film franco-sénégalais de Dyana Gaye
}

\section{Anaïs Vincent}

1 Le premier long-métrage de la jeune réalisatrice Dyana Gaye, Des étoiles, est sorti le 29 janvier dernier en salles. Sélectionné aux festivals Premier Plans d'Angers et de Toronto, ce film ambitieux raconte les parcours de jeunes migrants entre Dakar, New York et Turin. Cette narration triangulaire nous fait partager l'expérience de l'exil de ses trois protagonistes.

2 Sophie part de Dakar pour rejoindre son mari Abdoulaye à Turin. Mais ce dernier est parti tenter sa chance à New York. Pour les obsèques de son père, Thierno, un jeune New-Yorkais, découvre pour la première fois avec sa mère d'origine sénégalaise Dakar. On passe d'une ville à l'autre, d'une histoire à l'autre, d'une langue à l'autre, dans un mouvement fluide sans heurts ni effets.

3 Le choix de ces trois villes est apparu tout naturellement à la réalisatrice dont la mère est métisse d'origine franco-italo-malienne-sénégalaise et le père sénégalais immigré en France. Elle a souhaité construire une circulation entre trois villes familières.

4 Turin, cité industrielle a eu massivement recourt à l'immigration. Cependant, depuis quelques années, le flux s'inverse. En cause le durcissement des lois et la crise économique. Les immigrés touchés par le chômage sont expulsés. La Ligue du Nord, parti fasciste, gagne du terrain. Loin de cette vision dramatique, la réalisatrice choisit de mettre en scène un parcours d'intégration sans fausse note, à l'image de celui du jeune Rachid Khadiri Abdelmoura, un étudiant marocain vendeur de briquets, tout juste devenu docteur en ingénierie de la prestigieuse université polytechnique de Turin. Rachid n'a pas eu pourtant la chance de Sophie qui, dès son arrivée, est prise en charge par une association d'aide aux sans-papiers et est épaulée par la solidarité communautaire.

5 En Italie, le réseau associatif sénégalais est très actif et facilite l'intégration des nouveaux arrivants dans la société ${ }^{1}$. Très vite, elle trouve un logement, apprend la langue et un travail et tombe amoureuse. Vision positive et un peu idéaliste d'une 
immigration réussie. On se laisse pourtant porter par cette belle histoire. Pourquoi l'immigration devrait-elle être une expérience douloureuse?

6 Sophie a quitté Dakar alors que Thierno y pose le pied pour la première fois. Il porte un regard émerveillé et curieux, découvre la terre de ses ancêtres, sa famille. Sa mère éprise de liberté est mal comprise par les autres femmes. Les cultures se bousculent. Thierno a quitté sa ville alors qu'Abdoulaye y est venu pour des raisons économiques. New York, capitale du rêve américain, ville d'immigration par excellence, condense à elle seule les deux autres pays avec son Little Italy et son Little Senegal. Sa première expérience est plutôt négative mais grâce à ses connaissances, il parvient à s'en sortir.

7 Ces héros issus de la classe moyenne se croisent sans jamais se rencontrer. Auréolés de bienveillance ils cheminent vers la vie qu'ils ont choisi sans se retourner. Avec cette fiction la réalisatrice signe un tendre éloge à la liberté.

\section{NOTES}

1. Bruno Riccio, "Les associations de Sénégalais en Italie. Construction de citoyenneté et potentialités de co-développement”, in REVUE Asylon(s), n 3, mars 2008. 